\title{
Industry Updates
}

\section{Alloyed and Taniobis Collaborate to Develop Advanced Titanium and Refractory Alloy Metal Powders}

Alloyed Group, London, and German company Taniobis, announce a collaboration to identify, develop, produce, and implement innovative high-quality titanium and refractory-alloy metal powders for advanced manufacturing applications, including additive manufacturing

The partnership is said to enable a full end-to-end solution for

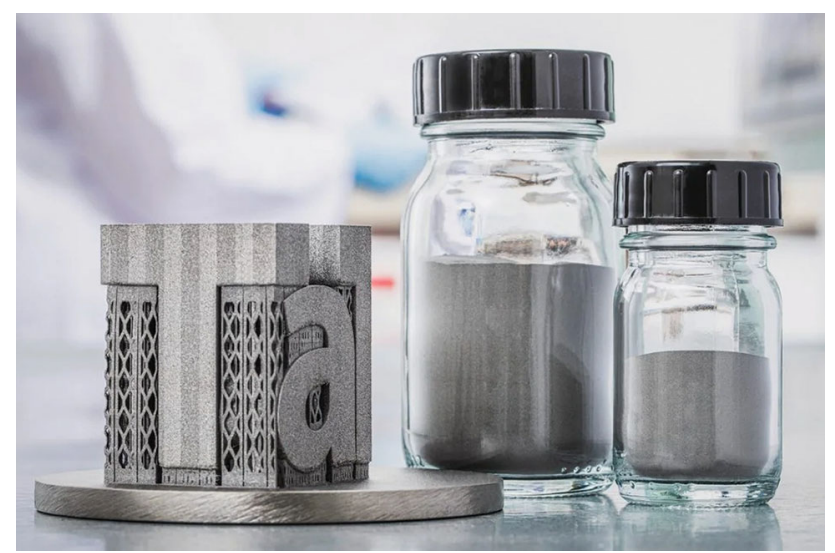

Alloyed and Taniobis will collaborate on the advancement of refractory alloy metal powders for additive manufacturing (Courtesy of Taniobis)

the material development process, including material analysis and qualification, material production, component design and performance, and also into pilot production. Alloyed and Taniobis will work on a broad spectrum of projects, some with third parties, for a range of applications across the medical, aerospace, and e-mobility industries.
"The Alloys By Design (ABD) platform, coupled with Taniobis' long-standing and world-leading expertise with tantalum and niobium materials, has the potential to open up some new and very exciting application areas for advanced manufacturing applications,"' says Michael Holmes, managing director of Alloyed.

"This capability together with the Betatype technology stack for adding performance to critical components makes this alliance even more powerful. We are excited to bring these developments to fruition in due course."

According to Katarzyna Kosowski, who heads Corporate Business Development \& Communication at Taniobis, "By collaborating with the experts at Alloyed and their exceptional ABD platform, we are extending our reach and capabilities into new and innovative areas for advanced manufacturing, and particularly for additive manufacturing.",

For more information: www.alloyed.com and www.taniobis. com.

\section{Cleveland-Cliffs Inc. Acquires Arcelor Mittal USA for Its Automotive and Other Markets}

Cleveland Cliffs Inc. announces that it has entered into a definitive agreement with ArcelorMittal S.A., in which ClevelandCliffs will acquire substantially all of the operations of ArcelorMittal USA LLC and its subsidiaries for approximately $\$ 1.4$ billion.

Upon closure of the transaction, Cleveland-Cliffs will be the largest flat-rolled steel producer in North America, with combined shipments of approximately 17 million net tons in 2019. The company will also be the largest iron ore pellet producer in North America, with 28 million long tons of annual capacity.

Lourenco Goncalves, chairman of the board, president, and CEO of Cleveland-Cliffs, will lead the expanded organization. "Steelmaking is a business where production volume, operational diversification, dilution of fixed costs, and technical expertise 
matter above all else," he says, "'and this transaction achieves all of these. ArcelorMittal is a world-class organization that we have long admired as our customer and our partner, and we know for a fact that they have taken good care of their U.S. assets."

"The acquisition of ArcelorMittal USA amplifies our position in the discerning automotive steel marketplace, and further improves our position in important U.S. markets such as construction, appliances, infrastructure, machinery, and equipment,' he says. "It also adds to our strong legacy raw material profile and growing finishing capabilities. The transaction will enable us to become a more efficient fully-integrated steel system, with the ability to realize all of our operational and financial goals."

For more information: www.clevelandcliffs.com.

\section{Exponent Celebrates Fifteen Years in Asia}

Exponent established its first office in China in 2015. Since then, they have provided clients with on-the-ground testing and analysis services for manufacturing operations in the Asia-Pacific region.

Today, Exponent employs forty technical staff across offices in Hong Kong, Shanghai, and Singapore, that work as a single integrated team, providing engineering and scientific consulting services to solve complex engineering and regulatory issues. Their services cover intellectual property, product liability, construction and infrastructure, oil, and gas, as well as specialized engineering failure analysis investigation for various consumer industries.

The technical staff support clients in the event of product incidents or production problems, helping them promptly resolve any technical problems or operational issues on the manufacturing floor or construction sites. Unlike ordinary analytical laboratories, Exponent's team takes a multi-disciplinary, fundamental science approach to uncover the true root cause of an issue, which can help companies reduce operational cost and risk in the long run.

During the current pandemic, Exponent's Asia team continues to support the high-impact and high-visibility needs of Fortune 500 and international companies while actively helping clients recover operations as workers return. They work to ensure clientsupplier quality teams maintain quality and yield on the manufacturing line during current travel restrictions, support failure analyses of large raw material and construction force majeure claims, validate facemask performance at the source, and perform tests to help diversify supply chains and screen raw materials as companies resume operations. The multi-disciplinary team, comprising data and computer scientists, polymer scientists, and corrosion engineers, has also developed analytical software and visualization platforms to help U.S. and EU-based clients monitor and track the quality of products remotely.

For more information: www.exponent.com.

\section{Optomec Wins Air Force Contract for Additive Manufacturing System to Repair Turbine Engine Components}

Optomec, Albuquerque, announces that the U.S. Air Force has awarded it a million-dollar contract to deliver a high-volume production machine for refurbishing turbine engine components, including titanium parts

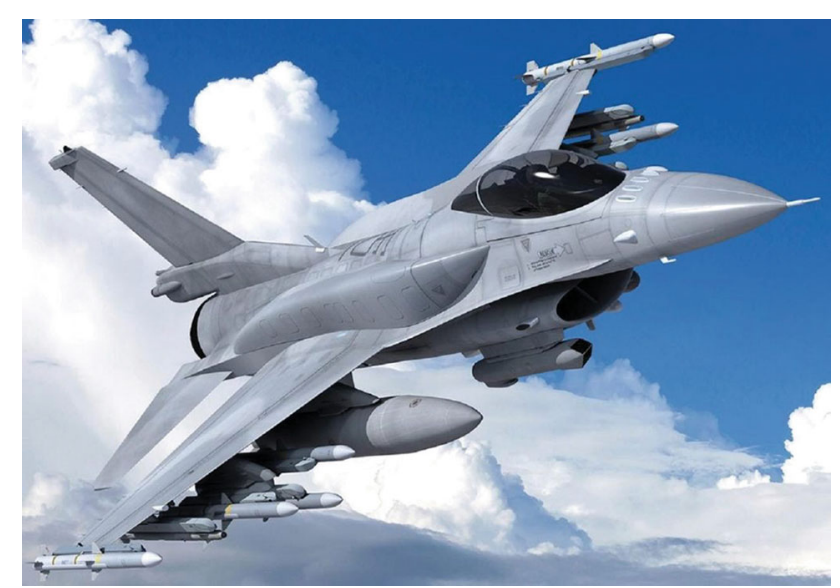

F-16 fighter jet

The equipment will include a range of state-of-the-art capabilities, including an automation system for batch processing, an oxygen-free controlled atmosphere, and an adaptive vision system. This automated additive repair system will be capable of tens of thousands of repairs per year, with an initial focus on tip refurbishment for turbine blades.

Optomec will also assist the U.S. Air Force in developing optimal process parameters for a range of target repairs. The solution will be installed at Tinker Air Force Base in Oklahoma City, which already hosts a world class comprehensive aircraft engine overhaul capability.

Optomec's metal additive repair solution is based on its proprietary laser engineered net shaping (LENS) technology, which was first commercialized more than 20 years ago. LENS uses a process called directed energy deposition in which a highly concentrated stream of metal powder is jetted into a molten pool created by the focus of a laser beam. By precisely controlling the melt pool and the powder flow, a high-performance metal structure is built up, either in the form of a fully printed part or as a local deposit onto an existing component to repair it.

For more information: http://www.optomec.com.

\section{RSP Technology's Rapid Solidification Process Produces Strong Nano-grained Aluminum}

RSP Technology, The Netherlands, announces that it has developed a superfast aluminum melt-spinning process that produces billets with an almost nano-grained crystalline structure that can be machined like conventional aluminum, but resulting parts will be as strong as titanium 


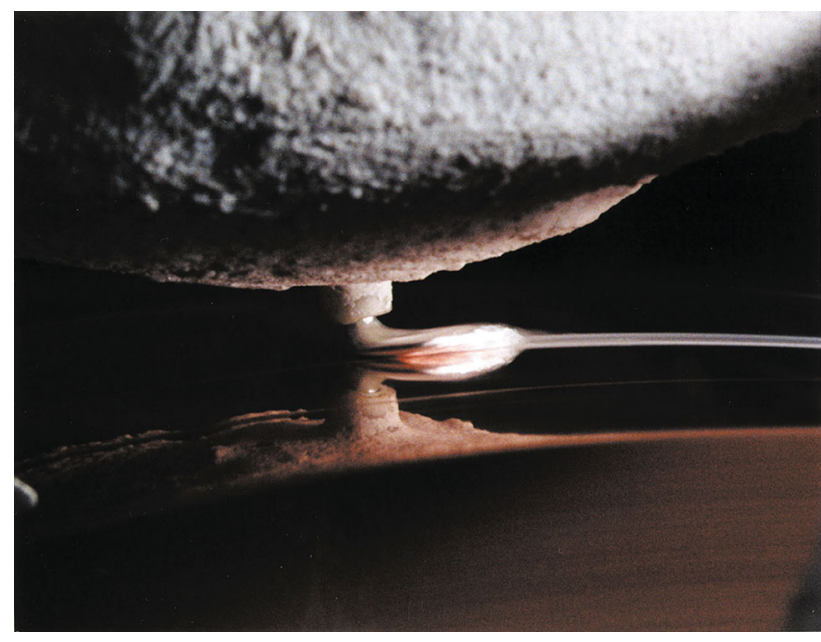

Melt-spinning close-up

During the melt-spinning process, molten aluminum hits a fastrotating wheel that almost instantaneously releases a continuous metal ribbon at room temperature. This ribbon is converted into flakes and finally into an extrusion product, after which a special heat treatment may be applied. The name "rapid solidification process" stems from the sudden temperature drop that takes place at a rate of more than $1,000,000{ }^{\circ} \mathrm{C}\left(1,800,000{ }^{\circ} \mathrm{F}\right)$ per second as the aluminum comes in contact with the wheel.

Thanks to the rapid quenching of the melt-spinning process, grain sizes are very small ( $\sim 2$ microns). Intermetallic phases and non-soluble constituents are refined and homogeneously distributed into the matrix and are characterized by a more favorable morphology. To a large extent, these factors contribute to the improved ductility of the alloy.

The natural maximum solubility imposes major limits to the content of alloying elements in conventional direct chill casting. However, the melt-spinning process generates ultrafast cooling rates. This creates great flexibility, thereby allowing the production of new and exotic alloy compositions such as AlSi40\%X or $\mathrm{AlFe} 15 \% \mathrm{X}$. Thus, melt-spinning is capable of providing custom solutions for applications that require special requirements.

Transmet Corp., Columbus, $\mathrm{OH}$, a manufacturer and supplier of rapidly solidified metals, will be the sole U.S. contact for sales and service for RSP Technology billet products.

For more information: www.transmet.com. and www.rsptechnology.com.

\section{Sandvik, Beamit, and Zare Join Forces to Additively Manufacture Parts of Advanced Metals}

Sandvik, Sweden, and partly owned Italian company Beamit, have joined forces with Zare to provide important advances in

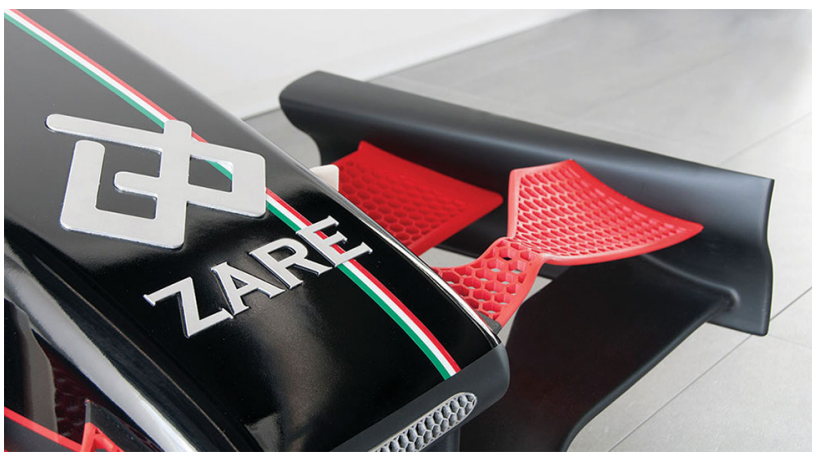

Post-processing of plastic parts

additive manufacturing (AM) of highly demanding metal parts.

In July 2019, Sandvik acquired a significant stake in Beamit, which recently acquired Zare, an AM service bureau. The Zare acquisition means that one of the largest independent AM service providers has been created, serving the most demanding industries. Beamit and Zare will continue to operate under their respective brand names, but activities will be consolidated under the Beamit Group.

Beamit is a trusted supplier of advanced metal AM components to demanding industries, including aerospace, automotive, and energy - with a number of relevant quality certifications, such as AS9100 for aerospace, and heat treatments with NADCAP approval. The company complements Sandvik's additive manufacturing products, which include the widest range of metal powders for AM and leading expertise across the entire AM value chain.

Zare, founded in 1963, has progressively grown into a leading, integrated AM service bureau-focusing on high-end components for demanding industries such as aerospace, automotive, motorsports, and energy - offering a full range of advanced AM services. The company has around 50 employees, a wide range of metal and polymer printers, and CNC machines for post-processing operations - as well as relevant quality certifications. 
"The new AM-constellation consisting of Sandvik and the Beamit Group is extremely strong-and will provide our customers with the opportunity to access the complementary and combined power of several leading players, covering the entire AM value chain," says Kristian Egeberg, president of Sandvik Additive Manufacturing.

For more information: www.home.sandvik.

\section{Using Digitally Distributed Manufacturing to Address Critical Needs}

When the new coronavirus struck, U.S. attempts to obtain and stockpile personal protective equipment, medical devices, and diagnostic testing equipment were too often hindered by local and global disruptions to supply chains. In a digital-first article from Advanced Materials \& Processes (AM\&P), ASM International's flagship magazine, a team from America Makes, Youngstown, $\mathrm{OH}$, share how they have mobilized the additive manufacturing community to work together to address the nation's medical equipment shortages during the COVID-19 pandemic.

The article also published in the October 2020 issue of AM\&P magazine.

It is the fourth installment in an AM\&P series on materials science and the coronavirus.

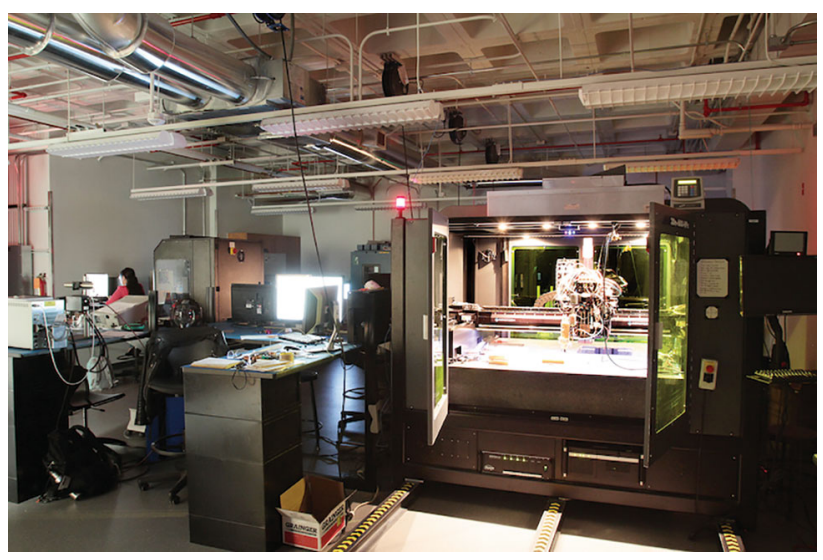

Keck Center facilities

For more information read the full article: https://www. asminternational.org/news/industry/-/journal_content/56/10192/ 42079993/NEWS.

Publisher's Note Springer Nature remains neutral with regard to jurisdictional claims in published maps and institutional affiliations. 